\title{
Inhibition of Acetylcholine Esterase and Choline Esterase by Benzethonium Chloride and Avoidance of the Benzethonium Chloride Carry-Over Inhibitory Effect
}

\author{
Zahur Zaman, Emmanuelle Speeleveld, Lutgarde Sneyers and Koenraad Desmet
}

Department of Clinical Chemistry, University Hospitals Leuven, Leuven, Belgium

\begin{abstract}
Summary: It has been shown that benzethonium chloride produces linear mixed-type inhibition of choline esterase and acetylcholine esterase. These enzymes also show-reagent-carry-over inhibition if the enzyme activities are measured in plastic cuvettes in which previously protein has been determined by the alkaline benzethonium chloride method. Choline esterase is about 10 -fold more sensitive to benzethonium chloride than acetylcholine esterase. With acetylthiocholine as substrate Michaelis-Menten constants for choline esterase and acetylcholine esterase are $85 \mu \mathrm{mol} / 1$ and $102 \mu \mathrm{mol} / 1$, respectively. Carry-over inhibitory effect of benzethonium chloride can be avoided by washing the cuvettes, after protein determination by the benzethonium chloride method, with $5 \mathrm{ml} / 1$ Triton X-100, $5 \mathrm{ml} / \mathrm{l}$ Tween 20 or $10 \mathrm{~g} / \mathrm{l}$ sodium dodecyl sulphate. The latter has a disadvantage in that it precipitates out at low temperatures. The dry slide method (Johnson \& Johnson) for serum choline esterase is free of the inhibitory effect until the concentration of benzethonium chloride in the sample reaches about $200 \mu \mathrm{mol} / \mathrm{l}$.
\end{abstract}

\section{Introduction}

In man acetylcholine can be hydrolyzed by choline esterase $^{1}$ ) and acetylcholine esterase ${ }^{1}$ ). Measurements of choline esterase activity are clinically important in cases of suspicion of toxicity with organophosphate pesticides and heritable deficiency of the enzyme with risk of prolonged apnea following anaesthesia with the muscle relaxant succinyl bischoline (suxamethonium). Choline esterase, being predominantly of hepatic origin, is also sometimes used as a liver function test (1). Determination of acetylcholine esterase, found in red blood cells, nerve endings and gray matter, is used as an additional confirmatory test for organophosphate poisoning $(2,3)$ and to diagnose neural tube defect (4).

Alkaline benzethonium chloride is used in one of the most frequently employed (5) turbidimetric methods for determination of total protein in urine and cerebrospinal fluid $(6,7)$.

\section{1) Enzymes: \\ Systematic name}

Acetylcholine acetylhydrolase (EC 3.1.1.7)

Acylcholine acylhydrolase (EC 3.1.1.8)
Trivial names

Acetylcholinesterase

Acetylcholine esterase

Red cell cholinesterase

Specific cholinesterase

True cholinesterase

Cholinesterase

Choline esterase

Butyrylcholinesterase

Non-specific cholinesterase

Pseudocholinesterase

Serum cholinesterase
All these tests have been automated and can be carried out on a single autoanalyzer. We have found that in such a situation both choline esterase and acetylcholine esterase are inhibited if the enzyme assay occurs in the same plastic cuvettes in which previously urinary total protein has been determined by the benzethonium chloride method and that the extent of this reagent-carry-over inhibition is related to the concentration of protein in urine (8).

In this article we have described the kinetic mechanism of inhibition of choline esterase and acetylcholine esterase by benzethonium chloride, a method of eliminating the carry-over inhibitory effect and the effect of benzthonium chloride on choline esterase as measured by the dry slide method.

\section{Materials and Methods}

Acetylthiocholine iodide and quinidine sulphate were purchased from ICN Biochemicals, CA, USA. Benzethonium chloride, butyrylthiocholine iodide, and sodium dodecyl sulphate were obtained from Sigma Chemical Co. St. Louis, MO, USA. 5,5'-Dithiobis (2nitrobenzoic acid) was from Janssen Chemica, Beerse, Belgium. All other chemicals were bought from E. Merck, Darmstadt, Germany.

Choline esterase and acetylcholine esterase activity assays and urinary total protein determinations were performed at $37^{\circ} \mathrm{C}$ on a BM/Hitachi 911 autoanalyzer (Boehringer Mannheim (BM), Mannheim, Germany). Choline esterase determination by the dry slide method was carried out at $37^{\circ} \mathrm{C}$ on Ektachem 700 XR (Johnson \& Johnson, Rochester, NY, USA). The latter method uses butyrylthiocholine as substrate. The effect of benzethonium chloride on this method was investigated by adding benzethonium chloride directly to the plasma samples. 
Determination of choline esterase and acetylcholine esterase on $\mathrm{BM} / \mathrm{Hitachi} 911$

We used the method of Lewis et al. (9) with a modified protocol. For choline esterase, $15 \mu \mathrm{l}$ plasma samples were added to $280 \mu \mathrm{l}$ $\mathrm{R}_{1}$, containing $0.58 \mathrm{mmol} / 1$ sodium bicarbonate and $0.32 \mathrm{mmol} / 1$ 5,5'-dithiobis (2-nitrobenzoic acid) in $0.1 \mathrm{~mol} / 1$ phosphate buffer, $\mathrm{pH}$ 8.0. After $1.25 \mathrm{~min}$ the reaction was started with addition of $20 \mu \mathrm{l}$ of $7.87 \mathrm{mmol} / \mathrm{l}$ acetylthiocholine $\left(\mathrm{R}_{2}\right)$ and monitored monochromatically at $415 \mathrm{~nm}$ between the 10th and 20th revolutions of the carousel. Each revolution of the BM/Hitachi 911 cuvette carousel takes $20 \mathrm{~s}$. For acetylcholine esterase the sample volume was $5 \mu \mathrm{l}$ and the $R_{1}$ was increased to $290 \mu \mathrm{l}$. When butyrylthiocholine $(7.87 \mathrm{mmol} / \mathrm{l})$ was used as a substrate, it simply replaced acetylthiocholine. Red blood cell haemolysates were produced as described by Lewis et al. (9).

\section{Kinetics of benzethonium chloride jnhibition}

Choline esterase and acetylcholine esterase activities were determined at final acetylthiocholine concentrations of $15,25,50,80$, 120,160 and $250 \mu \mathrm{mol} / 1$ in the absence and presence of 2.03 and $4.06 \mu \mathrm{mol} / \mathrm{l}$ of benzethonium chloride. In these experiments $R_{1}$ was $260 \mu \mathrm{l}$ for choline esterase and $270 \mu \mathrm{l}$ for acetylcholine esterase, $R_{2}$ was $20 \mu \mathrm{l}$ isotonic saline or benzethonium chloride solution and $R_{3}$ was acetylthiocholine $(20 \mu 1)$.

\section{Protein determination by the benzethonium chloride method}

Total protein in urine was determined as described by Iwata \& Nishikaze (6) using homemade reagents. Fifteen $\mu 1$ samples were added to $250 \mu \mathrm{l} \mathrm{R}_{1}$, containing $530 \mathrm{mmol} / \mathrm{l} \mathrm{NaOH}$ and $74 \mathrm{mmol} / \mathrm{l}$ EDTA-Na $a_{2}$. The reaction was started by addition of $100 \mu l R_{2}$ (consisting of $32 \mathrm{mmol} / \mathrm{l}$ benzethonium chloride) and monitored bichromatically at $505 \mathrm{~nm}$ (primary wavelength) and $700 \mathrm{~nm}$ (secondary wavelength) between the 15 th and 31 st revolutions.

Carry-over inhibition of choline esterase and acetylcholine esterase by benzethonium chloride and its elimination

New plastic cuvettes were placed in the BM/Hitachi 911 and choline esterase and acetylcholine esterase activities were measured. This was followed by determination of different concentration levels of urinary total protein by the benzethonium chloride method. Choline esterase and acetylcholine esterase activities were again assayed in the same cuvettes in which urinary protein had been determined. Carry-over inhibitory effect was estimated from the difference in the enzyme activities before and after protein determination.

To eliminate the carry-over inhibitory effect of benzethonium chloride, the analyzer was programmed to carry out an additional cell wash with "selective mode solution" $(0.2 \mathrm{mmol} / 1 \mathrm{HCl})$ from BM, $5 \mathrm{ml} / 1$ and $10 \mathrm{ml} / 1$ Triton X-100,10 g/l dodecyl sulphate or $5 \mathrm{ml} / 1$ and $10 \mathrm{ml} / 1$ Tween 20 after protein determination. Choline esterase and acetylcholine esterase activity measurements on the same samples were repeated in the same cuvettes.

\section{Results}

Reagent-carry-over inhibition of choline esterase and acetylcholine esterase by benzethonium chloride

When choline esterase and acetylcholine esterase activities were measured in the same cuvettes before and after determining urinary protein at different concentration levels it was found that previous contact of the plastic cuvette with benzethonium chloride has differential negative effect on both enzymes' activities (fig. 1). While choline esterase showed protein concentration dependent inhibition, acetylcholine esterase was only affected significantly when high protein concentrations levels had been assayed in the cuvette.

\section{Elimination of the inhibitory carry-over effect}

In one set of experiments choline esterase and acetylcholine esterase were assayed in the same cuvettes before and after urinary protein determinations. In another set, cuvettes were washed with detergent solutions following protein determinations and choline esterase and acetylcholine esterase activities were measured again. The results showed (fig. 2) that washing the cuvettes with $5 \mathrm{ml} / 1$ or $10 \mathrm{ml} / 1$ Triton $\mathrm{X}-100$ abolished the carry-over inhibitory effect of benzethonium chloride. Ten $\mathrm{g} / \mathrm{l}$ sodium dodecyl sulphate and $5 \mathrm{ml} / \mathrm{l}$ Tween 20 were equally effective. On the other hand, addition of these detergents to the cuvettes at the end of protein assay as $R_{4}$ and then washing the cuvettes in the usual way was totally ineffective. Washing the cuvettes with "selective mode solution" from BM also failed to remove the carry-over inhibition.

\section{Kinetics of benzethonium chloride inhibition of choline esterase and acetylcholine esterase}

Lineweaver-Burk plots for choline esterase and acetylcholine esterase in the absence and presence of different fixed concentrations of benzethonium chloride intersected above the $1 /[\mathrm{S}]$ axis indicating that benzethonium chloride produced mixed-type inhibition of these enzymes-affecting both $V_{\max }$ and $K_{\mathrm{m}}$. Results of only choline esterase are shown (fig. 3).

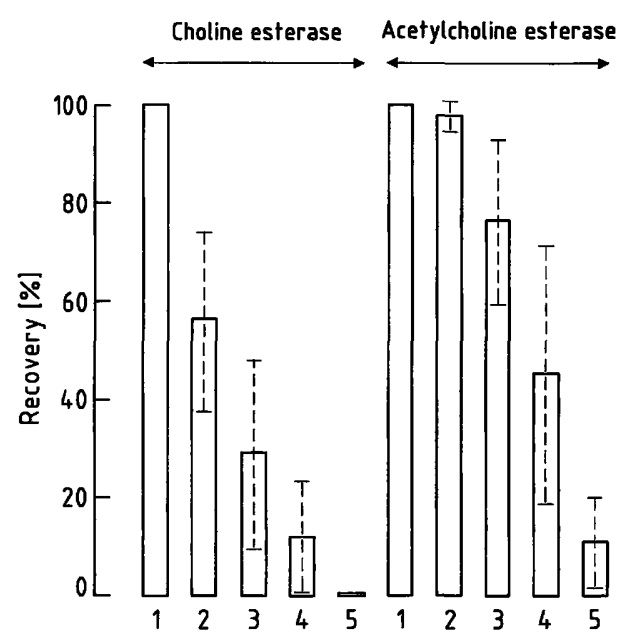

Fig. 1 Enzyme activity was determined in a fresh cuvette (1) and then again in the same cuvettes after protein determination in a blank saline sample (2) and in urine samples with protein concentrations of $1.2 \mathrm{~g} / 1(3), 5.5 \mathrm{~g} / \mathrm{l}(4)$ and $16 \mathrm{~g} / \mathrm{l}(5)$.

$1--\mid$ represents mean $\pm \mathrm{SD}(n=8)$. 


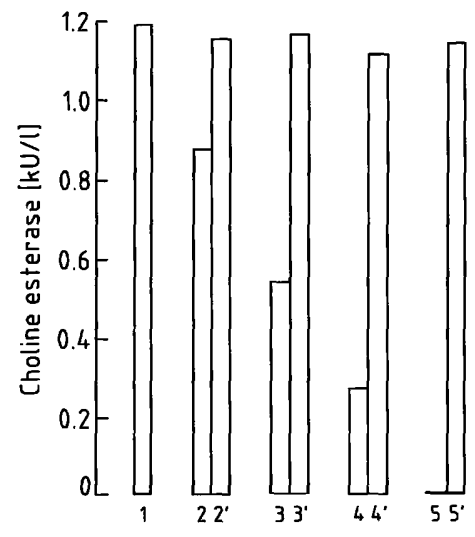

Fig. 2 Column 1 shows enzyme activity in fresh cuvettes. Columns 2, 3, 4 and 5 represent enzyme activities (of the same sample as in 1) in cuvettes in which protein had been determined by the benzethonium chloride method at concentrations levels of $0,1.34$, 5.9 and $14.1 \mathrm{~g} / \mathrm{l}$.

$K_{\mathrm{m},}, K_{\mathrm{i}}$ and $V_{\max }$ for choline esterase with acetylthiocholine as substrate were found to be $85 \mu \mathrm{mol} / \mathrm{l}, 35 \mathrm{nmol} / \mathrm{l}$ and $2.6 \mathrm{kU} / 1$ and for acetylcholine esterase $102 \mu \mathrm{mol} / \mathrm{l}$, $36 \mathrm{nmol} / 1$ and $22.5 \mathrm{kU} / 1$.

In the presence of $0.203 \mu \mathrm{mol} / \mathrm{l}$ benzethonium chloride, $V_{\max }$ and $K_{\mathrm{m}}$ of choline esterase changed to $1.2 \mathrm{kU} / \mathrm{l}$ and $128.7 \mu \mathrm{mol} / \mathrm{l}$, respectively. For acetylcholine esterase $2.03 \mu \mathrm{mol} / \mathrm{l}$ benzethonium chloride produced $V_{\max }$ of $11.2 \mathrm{kU} / \mathrm{l}$ and $K_{\mathrm{m}} 190 \mu \mathrm{mol} / 1$. Our $K_{\mathrm{m}}$ values for acetylcholine esterase and choline esterase agreed well with those of Lewis et al. (9).

\section{Effect of benzethonium chloride on choline esterase activity with butyrylthiocholine as substrate}

The effect of benzethonium chloride on choline esterase activity as measured by the dry slide method and with the BM/Hitachi 911 is shown in table 1. The results showed that the dry slide method remained unaffected by benzethonium chloride up to concentrations of 20.3 $\mu \mathrm{mol} / \mathrm{l}$. Even at a benzethonium chloride concentration ten times higher than this, choline esterase activity was reduced only by about $9 \%$.

On the other hand the wet chemistry method was extremely sensitive to benzethonium chloride and produced $29 \%$ inhibition of choline esterase at the benzethonium chloride concentration of $0.203 \mu \mathrm{mol} / \mathrm{l}$.

\section{Discussion}

Benzethonium chloride is a quaternary ammonium disinfectant that is used in skin cosmetics, in eye drops and as a topical antiseptic $(10,11)$. It has some structural (12) similarities with known acetylcholine esterase inhibitors (13). Therefore it might be expected to inhibit choline esterase and/or acetylcholine esterase. George \& Abernethy (14) have used a high concentration of ben-

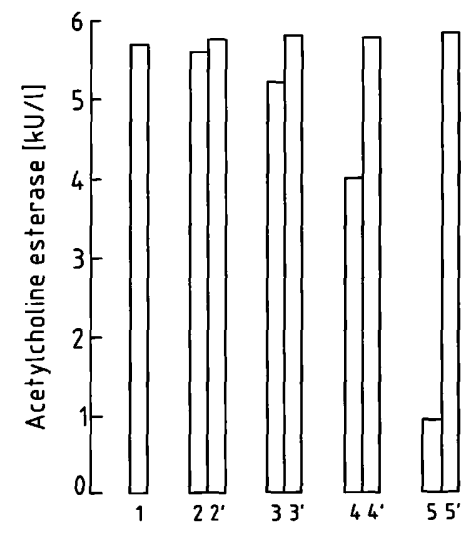

Columns 2', 3', 4' and 5' show activities in cuvettes that had been washed with $5 \mathrm{ml} / 1$ Triton $\mathrm{X}-100$ after protein determinations. The experiment was repeated with nine patient samples.

zethonium chloride to stop the acetylcholine esterase reaction, but they provide no data about the nature of this inhibitory action.

Our kinetic studies have revealed that the LineweaverBurk plots intersect above the $1 /[\mathrm{S}]$ axis (fig. 3). This indicates that benzethonium chloride produces linear mixed-type inhibition (15) of choline esterase and acetylcholine esterase. The equilibria describing this system can be written as follows:

$$
\begin{aligned}
& \mathrm{E}+\mathrm{S} \stackrel{K_{\mathrm{s}}}{=} \mathrm{ES} \stackrel{K_{\mathrm{p}}}{\longrightarrow} \mathrm{E}+\mathrm{P} \\
& +\quad+ \\
& \text { I I }
\end{aligned}
$$

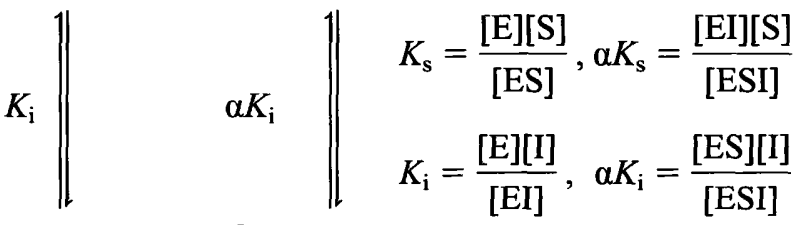

$$
\begin{aligned}
& \mathrm{EI}+\mathrm{S} \stackrel{\alpha K_{\mathrm{s}}}{=} \mathrm{ESI}
\end{aligned}
$$

Where

E is enzyme,

S is substrate,

I is inhibitor,

ES is enzyme-substrate complex,

EI is enzyme-inhibitor complex,

ESI is enzyme-substrate-inhibitor complex,

$P \quad$ is product,

$\alpha$ is a factor by which the dissociation constant of ESI complex must change to maintain the four enzyme species at equilibrium,

$K_{\mathrm{s}}$ and $K_{\mathrm{i}}$ are dissociation constants of ES and EI respectively.

This system may be regarded as a mixture of partial competitive inhibition and pure non-competitive inhibition. This is supported by the fact that the presence of inhibitor changes $K_{\mathrm{m}}$ (increased) and $V_{\max }$ (decreased) 


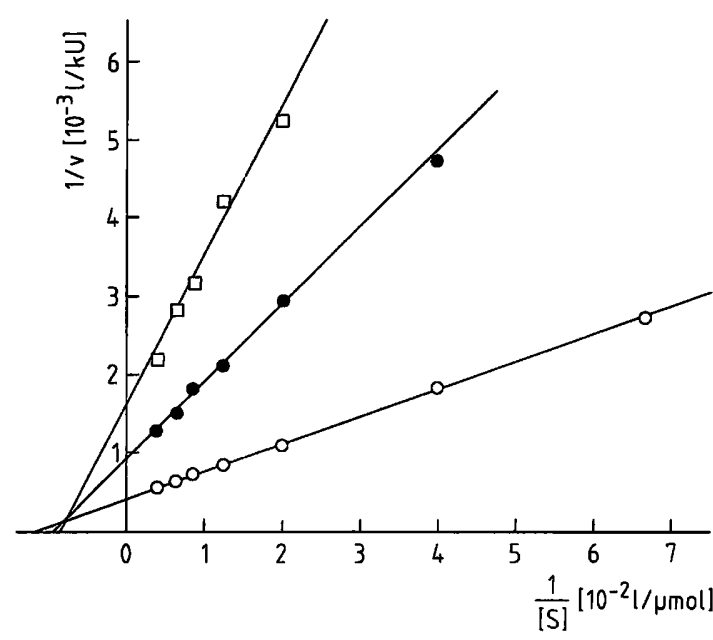

Fig. 3 Lineweaver-Burk plot for choline esterase in the presence of benzethonium chloride concentrations of 0 (O), $0.203 \mu \mathrm{mol} / 1(\bullet)$ and $0.406 \mu \mathrm{mol} / \mathrm{l}(\square)$.

of both choline esterase and acetylcholine esterase. Intersection of Lineweaver-Burk plots above the 1/[S] axis implies that $\alpha>1$. This is found to be the case. For choline esterase, $\alpha$ is found to be 1.9 and for acetylcholine esterase 2.2. In this system ESI is non-productive and at a sufficiently high concentration of inhibitor, velocity of the enzyme reaction would be reduced to zero (15). Acetylcholine esterase, however, is about 10 fold less sensitive to benzothonium chloride inhibition than choline esterase. This is deduced from the fact that whereas $50 \%$ decrease in $V_{\max }$ of acetylcholine esterase reaction with acetylthiocholine is produced by 2.03 $\mu \mathrm{mol} / 1$ benzethonium chloride, a similar reduction $V_{\max }$ of choline esterase is caused by $0.203 \mu \mathrm{mol} / 1$ benzethonium chloride.

It has been demonstrated that choline esterase and acetylcholine esterase are not only inhibited by the addition of benzethonium chloride to the reaction mixture but also when these enzymes are assayed in the plastic cuvettes in which previously total protein had been determined by the benzethonium chloride turbidimetric method. Furthermore the extent of inhibition shows dependence not only on the enzyme type but also on the concentrations of protein. This indicates that i) benzethonium chloride binds to plastic cuvettes

ii) binding of benzethonium chloride and/or benzethonium chloride-protein complex is greater in the presence of protein, and

iii) bound benzethonium chloride, though not completely dislodged by the routine washing procedure for cuvettes recommended by the manufacturers of the $\mathrm{BM} /$ Hitachi autoanalyzer, is capable of complexing with the enzymes.

The binding of benzethonium chloride and benzethonium chloride-protein complex was not limited to the plastic of the BM/Hitachi 911 analyzer cuvettes. The reagent-carry-over inhibition of choline esterase and acetylcholine esterase could be reproduced in disposable plastic cuvettes for spectrophotometers (results not shown).

We have shown that by programming an extra cell wash with $5 \mathrm{ml} / 1$ Triton X-100, $10 \mathrm{~g} / 1$ sodium dodecyl sulphate or $5 \mathrm{ml} / 1$ Tween 20 virtually all the bound benzethonium chloride can be removed. Use of a $10 \mathrm{~g} / 1$ sodium dodecyl sulphate solution, however, has one serious disadvantage in that the detergent precipitates out at low temperatures and thus cannot be kept on board an autoanalyzer in a cooled compartment.

In the dry slide choline esterase assay method butyrylthiocholine is used as substrate. Lack of inhibition of choline esterase by this method at benzethonium chloride concentrations that produce almost complete inhibition of choline esterase with acetylthiocholine by the conventional wet chemistry method, raised the possibility that with butyrylthiocholine as substrate choline esterase might not be inhibited by benzethonium chloride. This is found not to be the case (tab. 1). While by the wet chemistry method choline esterase is inhibited by $29 \%$ at $0.2 \mu \mathrm{mol} / 1$ benzethonium chloride, in the dry slide method $9 \%$ inhibition is observed at $203 \mu \mathrm{mol} / 1$ benzethonium chloride. This suggests that in the dry slide method benzethonium chloride is prevented from reaching the enzyme reaction layer by binding to some component of the slide and that this binding capacity for benzethonium chloride is saturated at about $200 \mu \mathrm{mol} / 1$.

Tab. 1 Effect of benzethonium chloride on choline esterase activity with butyrylthiocholine as substrate

\begin{tabular}{llllr}
\hline $\begin{array}{l}\text { Benzethonium chloride } \\
{[\mu \mathrm{mol} / 1]}\end{array}$ & $\begin{array}{l}\text { Choline esterase activity } \\
\text { (Ektachem 700 XR) } \\
{[\mathrm{kU} / 1]}\end{array}$ & $\begin{array}{l}\text { Inhibition } \\
{[\%]}\end{array}$ & $\begin{array}{l}\text { Choline esterse activity } \\
\text { (BM/Hitachi 911) } \\
{[\mathrm{kU} /]}\end{array}$ & $\begin{array}{l}\text { Inhibition } \\
{[\%]}\end{array}$ \\
\hline 0 & 2.35 & - & 2.01 & - \\
0.203 & 2.37 & none & 1.42 & 29 \\
2.03 & 2.35 & none & 0.26 & 87 \\
20.30 & 2.37 & none & 0.09 & 95 \\
203.0 & 2.15 & 9 & unmeasurable & 100 \\
\hline
\end{tabular}


Since the equilibrium of $\mathrm{E}$ (choline esterase) and I (benzethonium chloride) reaction is in the EI direction $\left(K_{\mathrm{i}}\right.$ $=36 \mathrm{nmol} / \mathrm{l}$ ) and I can be stripped from the EI in the slide, it suggests that the binding of benzethonium chloride to choline esterase is reversible and thus not convalent.

In conclusion we have demonstrated that

i) benzethonium chloride causes linear mixed-type inhibition of choline esterase and acetylcholine esterase,

ii) benzethonium chloride produces reagent-carry-over inhibition of choline esterase and acetylcholine esterase if these enzymes are assayed in plastic cuvettes in which

\section{References}

1. Brown SS, Kalow W, Pilz W, Whittaker M, Woronick CL. The plasma cholinesterases: a new perspective. Adv Clin Chem 1981; 22:1-123.

2. Long KR. Choline esterase activity as a biological indicator of exposure to pesticides. Int Arch Occup Environ Health 1975; $36: 75-86$.

3. Midtling JE, Barnett PG, Coye MJ, Velasco AR, Romero P, Clements CL, et al. Clinical management of field worker organophosphate poisoning. West J Med 1985; 142:514-8.

4. Smith AF. Amniotic fluid acetylcholinesterase assay and the antenatal detection of neural tube defects. Clin Chim Acta $1982 ; 123: 1-9$.

5. Hohnadel DC. Urine protein, total. In: Kaplan LA, Pesce AJ, editors. Clinical chemistry: theory, analysis and correlation. 2nd ed. St. Louis: cv Mosby Company, 1989:1060-5.

6. Iwata J, Nishikaze O. New micro-turbidimetric method for determination of protein in cerebrospinal fluid and urine. Clin Chem 1979; 25:1317-9.

7. Luxton RW, Patel P, Keir G, Thompson EJ. A micro-method for measuring total protein in cerebrospinal fluid by using benzethonium chloride in microtitre plate wells. Clin Chem 1989; 35:1731-4.

8. Zaman Z, Speeleveld E, Desmet K. Inhibition of choline esterase and acetylcholine esterase by benzethonium chloride [abstract]. Proceedings ACB National Meeting; 1995 May 15-19; previously total protein has been determined by the benzethonium chloride turbidimetric method - this is true whether the substrate is acetylthiocholine or butyrylthiocholine,

iii) the reagent-carry-over inhibition can be eliminated by washing the plastic cuvettes with $5 \mathrm{ml} / \mathrm{l}$ Triton X-100 ( $5 \mathrm{ml} / 1$ Tween 20 or $10 \mathrm{~g} / 1$ sodium dodecyl sulphate), and

iv) the dry slide method for choline esterase on Ektachem $700 \mathrm{XR}$ remains unaffected by benzethonium chloride until the concentration of the latter is $>200$ $\mu \mathrm{mol} / 1$.

Glasgow (UK). London: Association of Clinical Biochemists Ltd. 152.

9. Lewis PJ, Lowing RK, Gompertz D. Automated discrete kinetic method for erythrocyte acetylcholinesterase and plasma cholinesterase. Clin Chem 1981; 27:926-9.

10. Reynolds JEF, editor. Martindale, the extra pharmacopoeia. 29th ed. London: The Pharmaceutical Press, 1989:952.

11. Berkow R, editor. The Merck Manual, 14th ed. Rahway: Merck \& Co. Inc., 1982:2300-3.

12. Windholz $M$, editor. The Merck Index, 10th ed. Rahway: Merck \& Co. Inc., 1983:152.

13. Meyers FH, Jawetz E, Goldfien A, editors. Review of medical pharmacology. 7th ed. Los Altos: Lang Medical Publications, 1980:56-70.

14. George PM, Abernethy MH. Improved Ellman procedures for erythrocyte cholinesterase. Clin Chem 1983; 29:365-8.

15. Segel IH. Enzyme Kinetics. 1st ed. New York: John Wiley \& Sons, 1975:161-226.

Received February 24/May 12, 1997

Corresponding author: Zahur Zaman, MD, PhD, Department of Clinical Chemistry, University Hospitals Leuven, B-3000 Leuven, Belgium

Fax: +32 163328 96, e-mail: zahur.zaman@uz.kuleuven.ac.be 
